\title{
Interaction Between Autonomic Tone and the Negative Chronotropic Effect of Adenosine in Humans
}

\author{
WILLIAM H. KOU, K. CHING MAN, RAJIVA GOYAL, S. ADAM STRICKBERGER, \\ and FRED MORADY
}

\begin{abstract}
From the Cardiology Section, Veterans Affairs Medical Center, and the Cardiology Division,
Department of Internal Medicine, University of Michigan Medical Center, Ann Arbor, Michigan
\end{abstract}

\begin{abstract}
KOU, W.H., ET AL.: Interaction Between Autonomic Tone and the Negative Chronotropic Effect of Adenosine in Humans. Prior studies have demonstrated that sympathetic tone may influence the effects of adenosine on His-Purkinje automaticity, and that enhanced vagal tone may influence its effects on the sinus node. However, the interaction between autonomic tone and the effects of adenosine on the sinus node in humans remains unknown. Therefore, this study was designed to investigate the interaction between different states of autonomic tone and the bradycardiac response of the sinus node to adenosine. In 11 patients without structural heart disease who underwent a clinically indicated electrophysiology procedure, the sinus cycle length was measured before and after a 12-mg bolus of adenosine in the baseline state, during an infusion of $2 \mathrm{mcg} / \mathrm{min}$ of isoproterenol, after the administration of $0.2 \mathrm{mg} / \mathrm{kg}$ of propranolol, and again after the administration of $0.04 \mathrm{mg} / \mathrm{kg}$ of atropine. Adenosine significantly lengthened the sinus cycle length in the baseline state (760 \pm 165 vs $909 \pm 188 \mathrm{~ms}, P<0.05)$, during isoproterenol infusion (516 $\pm 67 \mathrm{vs} 766 \pm 146 \mathrm{~ms}, P<0.05)$, after propranolol ( $850 \pm 153 \mathrm{vs} 914 \pm 143 \mathrm{~ms}, P<0.05)$ and after the combination of propranolol and atropine (662 $\pm 76 \mathrm{vs} 801 \pm 121 \mathrm{~ms}, P<0.05)$. The degree of lengthening in sinus cycle length was significantly greater $(P<0.05)$ during isoproterenol infusion $(253$ $\pm 157 \mathrm{~ms}$, or $51 \% \pm 40 \%$ ) than in the baseline state (149 $\pm 85 \mathrm{~ms}$, or $20 \% \pm 12 \%$ ), after propranolol (68 $\pm 53 \mathrm{~ms}$, or $8 \% \pm 8 \%$ ), and after propranolol and atropine (140 $\pm 110 \mathrm{~ms}$, or $21 \% \pm 18 \%)$. The negative chronotropic effect of adenosine is influenced by autonomic tone. The effect of adenosine on the sinus node is accentuated by beta-adrenergic stimulation and unaffected by beta-adrenergic blockade or combined beta-adrenergic and cholinergic blockade. (PACE 1999; 22:1792-1796)
\end{abstract}

\section{Introduction}

Adenosine is a potent agent for termination of paroxysmal supraventricular tachycardia. ${ }^{1-3}$ Its pharmacological effects in cardiac tissue are mediated primarily by activation of adenosine $\mathrm{A}_{1}$ receptors. The $A_{1}$ receptor uses the same effector protein, guanine nucleotide binding protein (Gi) , as the cholinergic receptors. Activation of Gi results in a direct stimulatory effect on the outward

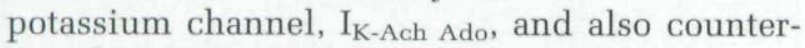
acts the effects of sympathetic stimulation by inhibition of adenyl cyclase. ${ }^{4-6}$ Experimental stud-

Address for reprints: William H. Kou, M.D., Section of Cardiology (111A), Veterans Affairs Medical Center, 2215 Fuller Road, Ann Arbor, MI 48105. Fax: (734) 769-7381.

Received November 3, 1998; revised February 22, 1999; accepted March 23, 1999. ies have demonstrated that vagal input may modulate the negative chronotropic effects of adenosine. ${ }^{7,8}$ However, no clinical studies have examined the influence of autonomic tone on adenosine's effects. Therefore, the purpose of this study was to examine the negative chronotropic effects of adenosine in the baseline state and during beta-stimulation, beta-adrenergic inhibition, and combined beta-adrenergic and cholinergic blockade.

\section{Methods}

\section{Characteristics of Subjects}

The subjects of this study were 11 patients who underwent a clinically indicated electrophysiology procedure for evaluation and/or treatment of paroxysmal supraventricular tachycardia (5 patients), the Wolff-Parkinson-White syndrome 
Table I.

Effect of Adenosine on Sinus

\begin{tabular}{|c|c|c|c|c|c|c|c|c|}
\hline \multirow[b]{2}{*}{ Case } & \multicolumn{4}{|c|}{ Baseline } & \multicolumn{4}{|c|}{ Isoproterenol } \\
\hline & before A & after A & $\Delta \mathrm{CL}$ & $\Delta \%$ & before $\mathrm{A}$ & after $\mathbf{A}$ & $\Delta \mathrm{CL}$ & $\Delta \%$ \\
\hline 1 & 1008 & 1272 & 264 & 26 & 636 & 852 & 216 & 34 \\
\hline 2 & 618 & 808 & 190 & 31 & 436 & 632 & 196 & 45 \\
\hline 3 & 1064 & 1136 & 72 & 7 & 576 & 896 & 320 & 56 \\
\hline 4 & 870 & 995 & 125 & 14 & 525 & 905 & 380 & 72 \\
\hline 5 & 665 & 710 & 45 & 7 & 505 & 590 & 85 & 17 \\
\hline 6 & 700 & 990 & 290 & 41 & 390 & 990 & 600 & 154 \\
\hline 7 & 800 & 1020 & 220 & 28 & 480 & 720 & 240 & 50 \\
\hline 8 & 620 & 732 & 112 & 18 & 556 & 813 & 257 & 46 \\
\hline 9 & 750 & 792 & 42 & 6 & 550 & 556 & 16 & 1 \\
\hline 10 & 536 & 700 & 164 & 31 & 496 & 636 & 140 & 28 \\
\hline 11 & 730 & 840 & 110 & 15 & 530 & 840 & 310 & 58 \\
\hline Mean $\pm S D$ & $760 \pm 165$ & $909 \pm 188$ & $149 \pm 85$ & $20 \pm 12$ & $516 \pm 67$ & $766 \pm 146$ & $253 \pm 157$ & $51 \pm 40$ \\
\hline
\end{tabular}

All intervals are expressed in milliseconds $\mathrm{A}=$ adenosine.

(1 patient), unexplained syncope (1 patient), or nonsustained ventricular tachycardia (4 patients). The inclusion criteria for this study were informed consent, the presence of sinus rhythm, and the absence of structural heart disease based on physical examination, electrocardiogram, and echocardiogram. Exclusion criteria consisted of asthma, spontaneous atrial or ventricular ectopy, and ingestion of a caffeine-containing beverage within 12 hours of the study. There were eight men and three women and their mean age was 50 \pm 15 years.

\section{Study Protocol}

The study protocol was approved by the Human Research Committee and was performed upon completion of the clinically indicated portion of the electrophysiology procedure. Midazolam was used for conscious sedation. A 6 or $7 \mathrm{Fr}$ electrode catheter was positioned in the high lateral right atrium. Five electrocardiographic leads and the right atrial electrogram were displayed on an oscilloscope and stored on an optical disc (Bard Labsystem 24, Boston, MA, USA), or recorded on paper at a speed of $25 \mathrm{~mm} / \mathrm{s}$ (Mingograf-7 recorder, Siemens-Elema, Solna, Sweden). Adenosine was administered on four occasions: (1) in the baseline state; (2) after 12 minutes of infusion of isoproterenol at a rate of $2 \mathrm{mcg} / \mathrm{min}$; (3) after discontinuation of the isoproterenol infusion and the infusion of $0.2 \mathrm{mg} / \mathrm{kg}$ of propranolol at a rate of 1-2 mg/min; and (4) after the administration of $0.04 \mathrm{mg} / \mathrm{kg}$ of atropine. These dosages of propranolol and atropine were used because a previous study demonstrated they were sufficient to result in complete beta-adrenergic and cholinergic blockade. ${ }^{9}$

Each administration of adenosine consisted of a $12-\mathrm{mg}$ dose that was rapidly infused into the side port of an intravascular sheath within a femoral vein. The negative chronotropic effect of adenosine was assessed by comparing the mean sinus cycle length before adenosine administration with the longest sinus cycle length during the 3 minutes after injection of adenosine.

\section{Statistical Analysis}

Continuous variables are expressed as mean \pm 1 SD. The Neuman-Keuls multiple comparison test was used to compare the effects of adenosine in the various autonomic states. $\mathrm{P}$ values less than 0.05 were considered significant.

\section{Results}

Table I lists the effects of adenosine on sinus cycle length in the baseline state, during isopro- 
Cycle Length

\begin{tabular}{cccccccc}
\hline \multicolumn{7}{c}{ Propranolol } & \multicolumn{7}{c}{ Propranol + Atropine } \\
\hline before A & after A & $\Delta$ CL & $\Delta \%$ & before A & after A & $\Delta$ CL & $\Delta \%$ \\
\hline 1148 & 1132 & -16 & -1 & 804 & 960 & 156 & 19 \\
684 & 872 & 188 & 27 & 552 & 652 & 100 & 18 \\
1127 & 1216 & 89 & 8 & 728 & 1000 & 272 & 37 \\
895 & 970 & 75 & 8 & 610 & 980 & 370 & 61 \\
705 & 755 & 50 & 7 & 630 & 750 & 120 & 19 \\
790 & 880 & 90 & 11 & 560 & 790 & 230 & 41 \\
820 & 910 & 90 & 11 & 680 & 710 & 30 & 4 \\
780 & 784 & 4 & 0.5 & 648 & 708 & 60 & 9 \\
830 & 900 & 70 & 8 & 720 & 780 & 60 & 8 \\
770 & 844 & 74 & 10 & 715 & 756 & 41 & 6 \\
800 & 800 & 0 & 0 & 640 & 730 & 90 & 14 \\
$850 \pm 153$ & $914 \pm 143$ & $68 \pm 53$ & $8 \pm 8$ & $662 \pm 76$ & $801 \pm 121$ & $140 \pm 110$ & $21 \pm 18$ \\
\hline
\end{tabular}

terenol infusion, after beta-adrenergic blockade, and after combined beta-adrenergic and cholinergic blockade. Adenosine resulted in significant lengthening of the sinus cycle length under each of the four conditions. The magnitude of lengthening in sinus cycle length, in its absolute value or as a percentage of the cycle length before the ad-

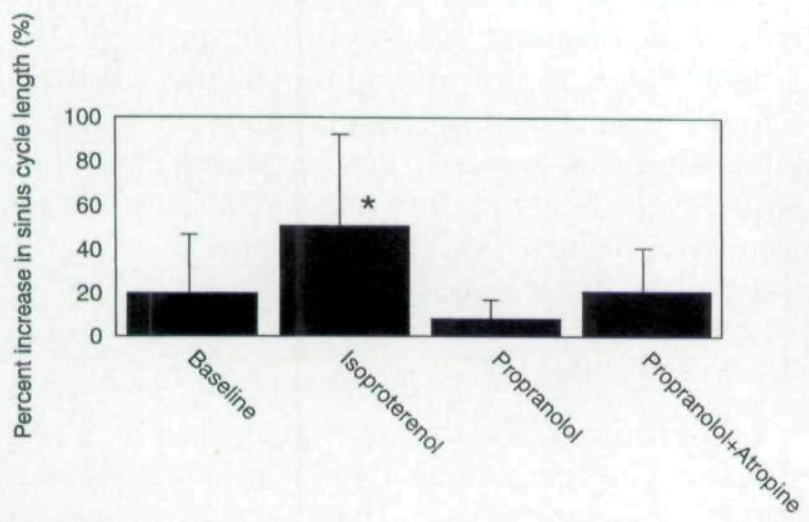

Figure 1. Effect of adenosine on the change of percentage of sinus cycle length in different autonomic states. The effect of adenosine on sinus cycle length was significantly greater during isoproterenol infusion than in the baseline state, after propranolol, or after propranolol and atropine. Vertical bars represent $1 S D$. ${ }^{*} P<0.05$. ministration of adenosine, was significantly greater during isoproterenol infusion $(253 \pm 157$ $\mathrm{ms}$, or $51 \% \pm 40 \%$ ) than in the baseline state (149 $\pm 85 \mathrm{~ms}$, or $20 \% \pm 12 \%, \mathrm{P}<0.05$ ), after betaadrenergic blockade $(68 \pm 53 \mathrm{~ms}$, or $8 \% \pm 8 \%$, P $<0.05$ ), or after combined beta-adrenergic and cholinergic blockade $(140 \pm 110 \mathrm{~ms}$, or $21 \% \pm$ $18 \%, \mathrm{P}<0.05$ ) (Figs. 1 and 2).

\section{Discussion}

\section{Main Findings}

The results of this study demonstrate that adenosine exerts a significant negative chronotropic effect regardless of the autonomic tone. However, the magnitude of adenosine's negative chronotropic effect is more than four times greater in the setting of beta-adrenergic stimulation than in the setting of beta-adrenergic blockade. In the presence of beta-adrenergic blockade, there is only an insignificant change of the magnitude of adrenergic effect before and after administration of atropine $(8 \% \pm 8 \%$ vs $21 \% \pm 18 \%$ or 68 $\pm 53 \mathrm{~ms}$ vs $140 \pm 110 \mathrm{~ms}, \mathrm{P}>0.05$ ). These findings suggest that the indirect effects of adenosine on the sinus node, mediated by the inhibition of adenyl cyclase, may be greater in magnitude than its direct effects, mediated by the $\mathrm{Gi}$ protein and activation of $\mathrm{I}_{\mathrm{k} \text {-Ach,ado }}$. 


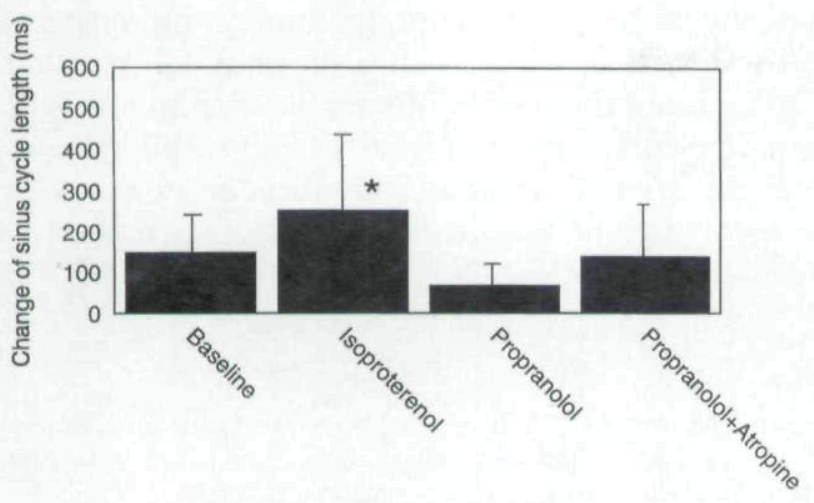

Figure 2. Effect of adenosine on the change of sinus cycle length in milliseconds in different autonomic states. The magnitude of increase in sinus cycle lengths is only significantly greater during isoproterenol infusion. Vertical bars represent $1 S D$. ${ }^{\star} P<0.05$.

\section{Results of Prior Studies}

No prior studies have investigated the interaction between autonomic tone and the effects of adenosine on the sinus node in humans. However, the results of this study are consistent with the results of prior studies that have investigated the effects of adenosine on the atrial monophasic action potential and the interaction between autonomic tone and the effects of adenosine on His-Purkinje automaticity. ${ }^{10,11} \mathrm{~A}$ more pronounced negative chronotropic effect on the His-Purkinje escape rhythm was observed when adenosine was administered in the presence of isoproterenol infusion. The increase in His-Purkinje cycle length was $41 \%$ before and $61 \%$ after intravenous infusion of isoproterenol. Similarly in the present study, adenosine increased the sinus cycle length by $20 \%$ before and $51 \%$ after administration of isoproterenol. However, in the present study adenosine maintained a significant negative chronotropic effect on sinus cycle length after pretreatment with propranolol, while its effect on His-Purkinje rhythmicity in the prior study ${ }^{11}$ was only minimal after pretreatment with propranolol. This difference suggests that adenosine's action on the sinus node is mediated by its direct (activation of $\mathrm{I}_{\mathrm{k} \text {-Ach Ado }}$ channels) and indirect (antiadrenergic) effect.

In the present study, propranolol did not significantly alter the response of the sinus node to adenosine. This finding is consistent with the finding of a study on the effect of adenosine on human atrial repolarization. ${ }^{10}$ The maximum shortening of atrial monophasic action potential duration by adenosine remained unaltered when subjects were pretreated with propranolol.

\section{Effect of Cholinergic Blockade}

Although animal studies showed that variations in vagal tone may have different effects on the bradycardic response to adenosine,,$^{7,8}$ this finding was not reproducible in regards to HisPurkinje automaticity in conscious humans during the Valsava maneuver or carotid sinus massage. ${ }^{10}$ The present study demonstrates that parasympathetic blockade has no significant influence on the magnitude of adenosine's negative chronotropic effect on the sinus node in the presence of $\beta$-blockade. Therefore, the vagal modulation of the electrophysiological effects of adenosine on human cardiac tissue is probably minimal.

\section{Limitations}

A limitation of this study is that the interaction between autonomic tone and the negative chronotropic effect of adenosine was assessed by the change in cycle length of the $\mathrm{P}$ wave. Since the sinus node electrogram was not recorded, it is not clear whether the change in $\mathrm{P}$ wave cycle length was purely the result of a direct negative chronotropic effect on the sinus node, or a combined result of its negative chronotropic effect on the sinus node and negative dromotropic effects on perinodal tissue. ${ }^{12,13}$ Another limitation is the variability in basal autonomic tone between individual patients. This was reflected by a wide range of sinus cycle lengths, 536-1,064 ms, in the baseline state. Lack of control of the baseline autonomic tone may, in part, influence the estimation of the magnitude of the effect of adenosine on the sinus cycle length, expressed in absolute number or a percentage.

\section{Clinical Implications}

Episodes of paroxysmal supraventricular tachycardia often are associated with sympathetic activation in response to hypotension, anxiety, or uncomfortable symptoms. The therapeutic effects 
of many antiarrhythmic agents, including verapamil, are antagonized by beta-adrenergic activation. ${ }^{14}$ However, the results of this study indicate that the effects of adenosine, at least on the sinus node, are potentiated by beta-adrenergic activation, suggesting that it is particularly well suited for the treatment of paroxysmal supraventricular

\section{References}

1. DiMarco JP, Sellers TD, Berne RM, et al. Adenosine: Electrophysiologic effects and therapeutic use for terminating paroxysmal supraventricular tachycardia. Circulation 1983; 68:1215-1263.

2. Cairns CB, Miemann JT. Intravenous adenosine in the emergency department management of paroxysmal supraventricular tachycardia. Ann Emerg Med 1991; 20:717-721.

3. Clarke B, Rowland E, Burnes PJ, et al. Rapid and safe termination of supraventricular tachycardia in children by adenosine. Lancet 1987; 1:299-301.

4. Lerman BB, Bellardinelli L. Cardiac electrophysiology of adenosine. Basic and clinical concepts. Circulation 1991; 83:1499-1509.

5. DiMarco JP. Adenosine. In Zipes, Jalife (eds.): Cardiac Electrophysiology. From Cell to Bedside. Philadelphia, PA, W. B. Saunders Company, 1995, pp. 1336-1344.

6. Shryock JC, Bellardinelli L. Adenosine and adenosine receptors in the cardiovascular system: Biochemistry, physiology, and pharmacology. Am J Cardiol 1997; (12A):2-10.

7. Pelleg A, Mitsuoka T, Mazgalev T. Interacting negative chronotropic effects of adenosine and vagus nerve on the canine sinus node. Cardiovas Res 1990; 22:55-61. tachycardia. Another implication of the results of this study is that, because propranolol does not potentiate the effects of adenosine, patients with paroxysmal supraventricular tachycardia who are being treated with a beta-adrenergic blocking agent do not require a reduction in dosage of adenosine.

8. Monteiro EC, Ribeiro JA. Adenosine and bradycardic response to vagus nerve stimulation in rats. Eur J Pharmacol 1991; 204:193-202.

9. Jose AD, Taylor RR. Autonomic blockade by propranolol and atropine to study intrinsic myocardial function in man. J Clin Invest 1969; 48: 2019-2024.

10. Nunain SO, Garatt C, Paul V, et al. Effect of intravenous adenosine on human atrial and ventricular repolarization. Cardiovasc Res 1992; 26:939-943.

11. Lerman BB, Wesley RC, DiMarco JP, et al. Antiadrenergic effects of adenosine on His-Purkinje automaticity. Evidence for accentuated antagonism. J Clin Invest 1988; 82:2127-2135.

12. Favale S, DiBiase M, Rizzo V, et al. Effect of adenosine and adenosine-5'-triphosphate on atrioventricular conduction in patients. J Am Coll Cardiol 1985; 5:1212-1219.

13. West GA, Belardinelli L. Sinus slowing and pacemaker shift caused by adenosine in rabbit SA node. Pflugers Arch 1985; 403:66-74.

14. Morady F, Kou WH, Kadish AH, et al. Epinephrine-induced reversal of verapamil's electrophysiologic and therapeutic effects in patients with paroxysmal supraventricular tachycardia. Circulation 1989; 79:783-790. 
Copyright of Pacing \& Clinical Electrophysiology is the property of Blackwell Publishing Limited and its content may not be copied or emailed to multiple sites or posted to a listserv without the copyright holder's express written permission. However, users may print, download, or email articles for individual use. 